\title{
Failure of Fourth-Generation Enzyme Immunoassay in HIV Screening and Plasma HIV-1 RNA Detection in Recent High-Risk Behavior
}

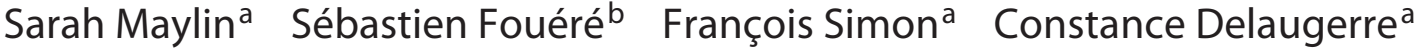 \\ ${ }^{a}$ Laboratoire de Microbiologie, and ${ }^{\text {b}}$ Unité des MST, AP-HP-Hôpital Saint Louis, Paris, France
}

\section{Key Words}

HIV · Enzyme immunoassay · Sexually transmitted infection

\begin{abstract}
Acute HIV infection was not detected in a young man presenting symptoms of sexual disease infection using fourthgeneration screening tests combining HIV-specific antibody and p24 antigen. Detection of plasma HIV-1 RNA concomitant with screening tests may be proposed in individuals presenting with a symptomatic sexually transmitted infection.

(c) 2013 S. Karger AG, Basel
\end{abstract}

In February 2012, a 22-year-old male American student came to the sexually transmitted infections (STI) department of Saint Louis Hospital (Paris, France) seeking medical advice. The patient was complaining of anal discomfort and discharge. He reported unprotected receptive anal intercourse with a man 7 days before his visit. Rectoscopy showed nonspecific rectitis with erythematous mucosa.

Rectal and throat swabs as well as a first-catch urine sample were taken for a Chlamydia trachomatis nucleic acid amplification test (NAAT) and a Neisseria gonor-

\section{KARGER}

E-Mail karger@karger.com

www.karger.com/int rhoeae NAAT and culture. The patient was also screened for syphilis, HIV, HBV, and HCV. He was given a single 500-mg dose of ceftriaxone intramuscularly and a single 1,000-mg dose of azithromycin orally.

$N$. gonorrhoeae was detected in the pharyngeal and rectal specimens. The enzyme immunoassay (EIA) Architect HIV Ag/Ab Combo ${ }^{\circledR}$ (Abbott Diagnostic, Rungis, France), currently used in our laboratory to screen HIV infection, was negative (index 0.42 , signal-to-cutoff ratios of 1.0 or greater are considered reactive). Serological tests for syphilis diagnosis, i.e. TPHA and VDRL performed via hemaglutination assay and a flocculation test (Bio-Rad, Marnes-la-Coquette, France), respectively, were negative. Serological screening for anti-HCV antibody, and HBs antigen using the Architect EIA were negative.

One week later, the patient came back to collect his results and declared that he had suffered from influenzalike symptoms during the week. A serological control was performed with the Architect HIV Ag/Ab Combo test, which was positive (index 179); the Western blot remained negative but plasma HIV-1 RNA quantification $\left(\right.$ COBAS $^{\circledR}$ Taqman HIV-1 v2.0; Roche, France) was up to $10^{7}$ copies $/ \mathrm{ml}$. The first sample stored was tested and 25,320 copies of HIV-1 RNA/ml were found. The Architect HIV Ag/Ab Combo negativity for p24 antigen detec- 
tion was in accordance with the assay limit considered to be $<2$ IU p $24 / \mathrm{ml}$. This p24 antigen level corresponds to a level of HIV-1 RNA above 30,000 copies/ml [1].

We confirmed the absence of reactivity in the first sample with VIDAS ${ }^{\circledR}$ HIV DUO ULTRA (bioMérieux, Marcy l'Etoile, France) and with Genscreen ${ }^{\circledR}$ HIV1/2 version 2 (Bio-Rad), both highly sensitive fourth-generation EIA with a p24 antigen detection limit of $<2 \mathrm{IU} / \mathrm{ml}$.

Genotypic analysis of the reverse transcriptase and protease genes showed that the infective HIV-1 virus belonged to the CRF02_AG viral subtype without any antiretroviral drug resistance-associated mutation. Of note, the CRF02_AG subtypes represent half of the non-B HIV-1 subtypes circulating in France and 15\% in the homosexual population [2].

Diagnosis of acute HIV infection is a major goal for the patient and also for limiting the HIV epidemic. Using robust screening tests combining anti-HIV-specific antibody and HIV-1 p24 antigen (fourth-generation EIA) is recommended for diagnosis in the earlier phase after contamination. We report a case of failure of fourth-generation screening tests in a young man presenting symptoms of sexual disease infection. These fourth-generation screening EIA, detecting both HIV-1 p24 antigen and anti-HIV-specific antibody, are positive in around $90 \%$ of acute infections defined by the presence of HIV-1 RNA and the lack of detectable anti-HIV antibody in a seroconversion panel $[1,3,4]$.

Indeed, 57 of the 64 (89\%) specimens from recently HIV-1 (B subtype)-infected individuals were found to be reactive with the Architect HIV Ag/Ab Combo, while no HIV antibody was detected by any antibody-based methods $[1,5]$. Generally the seroconversion panel includes a majority of HIV-1 B subtypes, and data with non-B subtypes are limited. A lower sensitivity to detect the p24 protein of an HIV-1 CRF02_AG subtype, as in our case, could be suggested [6].

Although HIV-1 RNA detection could be a gold standard for the diagnosis of acute infection, its limitations include: its cost, more complex technology, a longer waiting period for the results, and the risk of false-negative detection due to the genetic variability of amplification targets. However, our case highlights the importance of assessing plasma HIV-1 RNA in cases of symptomatic STI even in the absence of primary HIV infection symptoms. Moreover, HIV-1 RNA detection could be useful mainly for infections with a very short incubation period, e.g. in symptoms of N. gonorrhoeae infection, because of the negativity of fourth-generation EIA. Different guidelines currently recommend an HIV viral load test in addition to an antibody test for patients with symptoms consistent with the acute retroviral syndrome and recent high-risk behavior [7, 8]. However, several cost-effectiveness studies of routine HIV screening in populations of men who have sex with men have analyzed the combination of viral load testing (pooled or individual) with antibody testing. Use of HIV viral load testing in influenzalike illness (symptom-based) should prevent more infections compared to expanded annual antibody screening alone with third-generation antibody tests [9]. Alternatively, testing via fourth-generation immunoassay every 6 months should detect a greater number of infections, is more economically efficient, and may obviate the benefits of acute HIV screening via molecular biology [10].

The high viral replication during acute HIV infection leads to a major risk of transmission. Models and phylogenetic studies incriminate this acute, hyperinfectious phase as the culprit that, despite its short duration, drives HIV epidemics [11-13]. After the eclipse phase following infection, plasma HIV-1 RNA and then p24 antigen appear, followed by HIV-specific antibodies in a generally uniform 7- to 21-day sequence [13]. Negative screening test results during this period could lead to critical missed opportunities to interrupt onward HIV transmission. Our case suggests that detection of the HIV viral load concomitant with serologic screening tests may be proposed in individuals presenting with a symptomatic STI.

\section{References}

1 Pandori MW, Hackett J Jr, Louie B, Vallari A, Dowling T, Liska S, Klausner JD: Assessment of the ability of a fourth-generation immunoassay for human immunodeficiency virus (HIV) antibody and p24 antigen to detect both acute and recent HIV infections in a high-risk setting. J Clin Microbiol 2009;47: 2639-2642.

$\checkmark 2$ Chaix M-L, Seng R, Frange P, Tran L, Avettand-Fenoël V, Ghosn J, Reynes J, Yazdanpanah Y, Raffi F, Goujard C, Rouzioux C, Meyer
L, ANRS PRIMO Cohort Study Group: Increasing HIV-1 non-B subtype primary infections in patients in France and effect of HIV subtypes on virological and immunological responses to combined antiretroviral therapy. Clin Infect Dis 2013;56:880-887.

3 Speers D, Phillips P, Dyer J: Combination assay detecting both human immunodeficiency virus (HIV) p24 antigen and anti-HIV antibodies opens a second diagnostic window. J Clin Microbiol 2005;43:5397-5399. 
-4 Weber B, Gürtler L, Thorstensson R, Michl U, Mühlbacher A, Bürgisser P, Villaescusa R, Eiras A, Gabriel C, Stekel H, Tanprasert S, Oota S, Silvestre M-J, Marques C, Ladeira M, Rabenau H, Berger A, Schmitt U, Melchior W: Multicenter evaluation of a new automated fourth-generation human immunodeficiency virus screening assay with a sensitive antigen detection module and high specificity. J Clin Microbiol 2002;40:1938-1946.

-5 Patel P, Bennett B, Sullivan T, Parker MM, Heffelfinger JD, Sullivan PS: Rapid HIV screening: missed opportunities for HIV diagnosis and prevention. J Clin Virol 2012;54:42-47.

-6 Ly TD, Plantier JC, Leballais L, Gonzalo S, Lemée $V$, Laperche $S$ : The variable sensitivity of HIV Ag/Ab combination assays in the detection of p24Ag according to genotype could compromise the diagnosis of early HIV infection. J Clin Virol 2012;55:121-127.
7 Yeni P, Groupe d'Expert: Prise en Charge Médicale des Personnes Infectées par le VIH. Paris, La Documentation Française, 2010.

-8 Branson BM, Handsfield HH, Lampe MA, Janssen RS, Taylor AW, Lyss SB, Clark JE: Revised recommendations for HIV testing of adults, adolescents, and pregnant women in health-care settings. MMWR Recomm Rep 2006;55:1-17, quiz CE1-4.

-9 Juusola JL, Brandeau ML, Long EF, Owens DK, Bendavid E: The cost-effectiveness of symptom-based testing and routine screening for acute HIV infection in men who have sex with men in the USA. AIDS 2011;25:17791787.
0 Long EF: HIV screening via fourth-generation immunoassay or nucleic acid amplification test in the United States: a cost-effectiveness analysis. PLoS One 2011;6:e27625.

11 Brenner BG, Roger M, Routy J-P, Moisi D, Ntemgwa M, Matte C, Baril J-G, Thomas R, Rouleau D, Bruneau J, Leblanc R, Legault M, Tremblay C, Charest H, Wainberg MA: High rates of forward transmission events after acute/early HIV-1 infection. J Infect Dis 2007; 195:951-959.

12 Frange P, Meyer L, Deveau C, Tran L, Goujard C, Ghosn J, Girard P-M, Morlat P, Rouzioux C, Chaix M-L, French ANRS CO6 PRIMO Cohort Study Group: Recent HIV-1 infection contributes to the viral diffusion over the French territory with a recent increasing frequency. PLoS One 2012;7:e31695.

13 Cohen MS, Shaw GM, McMichael AJ, Haynes BF: Acute HIV-1 infection. N Engl J Med 2011;364:1943-1954 